\title{
KANT E SCHOPENHAUER SOBRE A NATUREZA DA FILOSOFIA MORAL
}

\author{
Aguinaldo Pavão \\ Universidade Estadual de Londrina
}

\begin{abstract}
Abstratct: This paper aims to examine Schopenhauer's criticism of the Kantian understanding of moral philosophy. The basic reference for this examination is Schopenhauer's book On the Basis of Morality. The paper tries to sustain the thesis that the nature of Kant's moral philosophy can be defended successfully from the negative assessment made by Schopenhauer.
\end{abstract}

Key-words: Moral philosophy, morals laws, philosophical clarifications, moral prescription, theological moral.

Resumo: Este artigo tem como objetivo examinar a crítica de Schopenhauer à compreensão kantiana de filosofia moral. A referência básica para esse exame é o livro Sobre o Fundamento da Moral de Schopenhauer. O artigo tenta sustentar a tese de que a natureza da filosofia moral segundo Kant pode ser defendida com sucesso frente à apreciação negativa que dela faz Schopenhauer.

Palavras-chave: Filosofia moral, leis morais, elucidações filosóficas, prescrição moral, moral teológica.

Schopenhauer, em Sobre o Fundamento da Moral, oferece sua resposta à questão proposta pela Sociedade Real Dinamarquesa de Ciências

\footnotetext{
1 Artur Schopenhauer. Sobre o Fundamento da Moral. (1995). As citações indicarão o número do parágrafo seguido do número da página da edição citada. Eventualmente farei cotejos com o texto em alemão: Über die Grundlage der Moral. Kleinere Schriften. Sämtliche Werke, Band III: Bearbeitet und Heraugegebt von Wolfgang Frhr. Von Löhnheysen. Frankfurt am Main: Suhrkamp, 1998, p. 629-815.
} 
de Copenhague, referente à fonte e o fundamento da filosofia moral" ${ }^{2}$. A resposta de Schopenhauer consiste na defesa da tese de que a

compaixão (Mitleids), quer dizer, a participação totalmente imediata, independente de qualquer outra consideração, no sofrimento de um outro (...) é a base efetiva de toda a justiça livre e de toda a caridade genuína. Somente enquanto uma ação dela surgiu é que tem valor moral, e toda ação que se produz por quaisquer outros motivos não tem nenhum (SFM $\S 16: 129)$.

A compaixão como fundamento da moral envolve não apenas o abandono de toda perspectiva eudemonista e de qualquer possibilidade de se assentir a alguma forma de egoísmo racional. Além disso, ela também implica um rechaço das tentativas de fundar a moral em bases teológicas. Embora Schopenhauer acredite que Kant não conseguiu livrar verdadeiramente a ética do egoísmo e da teologia, a reflexão moral kantiana é considerada mais vantajosa que as éticas anteriores e a última e mais significativa tentativa de fundamentá-la (Cf. $S F M \S 2: 14$ ). Sendo assim, a filosofia moral de Kant é eleita como alvo de análise e contraposição com o que Schopenhauer julga ser pertinente e consistente numa reflexão filosófica sobre a moral. A fim de preparar o caminho para fundamentar a moral na compaixão, Schopenhauer apresenta uma contundente crítica à Fundamentação da Metafísica dos Costumes $(F M C)^{3}$ de Kant. Essa crítica compõe aproximadamente toda a primeira metade de seu livro. Ela encontrase dividida em nove parágrafos (§§ 3-11), reunidos num capítulo intitulado "Crítica ao fundamento dado à moral por Kant". Nesta parte da obra, Schopenhauer analisa e ataca os pontos principais da obra de Kant. Pode-se afirmar que sua leitura é minuciosa ${ }^{4}$. Ela aponta detalhadamente várias

\footnotetext{
2 "Quer a sociedade que se reflita e se trate cuidadosamente da seguinte questão: A fonte e 0 fundamento da moralidade da filosofia moral devem ser buscados numa idéia de moralidade contida na consciência imediata e em outras noções fundamentais que dela derivam ou em outro princípio do conhecimento?" (SFM: 4).

3 Immanuel Kant. Fundamentação da Metafísica dos Costumes. (1995). Edição alemã: Grundlegung zur Metaphysik der Sitten, Werkausgabe VII. Ed. W. Weischedel. Frankfurt: Surkamp, 1991.

${ }^{4}$ É preciso, aqui, que entendamos "cuidadosa" como um qualificadora do caráter minucioso do exame feito pelo autor do MVR. Schopenhauer mesmo diz: "Dedicarei (..) à mais nova tentativa de fundar a ética, à kantiana, uma investigação crítica e por certo bem detalhada" (SFM § 2: 14). Faço essa ressalva, pois acredito que muitos dos ataques de Schopenhauer a Kant talvez devam ser avaliados como precipitados. Portanto, embora em SFM Schopenhauer nos ofereça minuciosas análises da ética
} 
inconsistências que teriam sido cometidas por Kant. Acredito que as supostas inconsistências possam ser agrupadas em três principais tópicos: a) rejeição da compreensão kantiana acerca da natureza da filosofia moral e, por conseguinte, de seus conceitos fundamentais; b) avaliação de que o imperativo categórico se apóia no egoísmo (e demais críticas às fórmulas e sentido do imperativo categórico) e c) inconsistência da tentativa de justificação apriorística da moral oferecida por Kant.

Gostaria, neste texto, de avaliar o ponto (a) da crítica de Schopenhauer a Kant. A crítica à compreensão kantiana sobre a natureza da filosofia moral é desenvolvida basicamente a partir de três argumentos ${ }^{5}$.

1. Kant comete uma petição de princípio ao admitir, já no prefácio da $F M C$, a existência de leis morais puras, existência esta que deveria antes ser investigada e demonstrada e não pressuposta (Cf. SFM § 4: 21).

2. A forma legislativo-imperativa da ética é equivocada, pois não corresponde ao verdadeiro trabalho de análise filosófica, que deve se ater ao "esclarecimento do dado" e não de algo que deve acontecer (SFM§ 4: 20-21).

3. "Kant emprestou da moral teológica, silenciosamente e sem ser visto, a forma imperativa da ética, cujas pressuposições, e portanto a teologia, estão no fundamento dela” (SFM§ 4: 27).

de Kant, isso não significa que tais análises tenham sido exaustivas na ponderação das possíveis respostas às objeções formuladas.

5 Pode-se considerar um outro argumento, o mencionado por Welsen em seu artigo "Schopenhauer's Interpretation of the Categorical Imperative". a saber, o da alegada contradição entre vontade livre e prescrição de leis a ela (WELSEN 2005: 770). Em MVR Schopenhauer afirma: "é uma contradição flagrante denominar a Vontade livre e, no entanto prescrever-lhe leis segundo as quais deve querer" (MVR IV § 53, p. 354, tradução JB). Por que seria uma contradição ser livre e ter deveres? Somente posso ter autênticos deveres se sou livre para seguí-los ou não. Por certo, essa resposta somente adquire validade numa perspectiva não-schopenhauriana, sendo perfeitamente aceitável em termos kantianos. Mas a vontade individual (particular, do homem como fenômeno) não é livre para Schopenhauer. 


\section{Sobre a suposta petição de princípio cometida por Kant}

A crítica de Schopenhauer acerca da precipitação de Kant e de uma suposta petição de princípio na $F M C$, à primeira vista, parece correta. Kant afirma no prefácio da $F M C$ que a necessidade de uma filosofia moral pura "ressalta com evidência da idéia comum do dever e das leis morais. Toda a gente tem de confessar que uma lei que tenha de valer moralmente, isto é, como fundamento duma obrigação, tem de ter em si uma necessidade absoluta" (FMC BA VIII/Ak 389). Kant está realmente pressupondo o que deveria ser demonstrado? Não há como negar que Kant esteja pressupondo a “idéia comum de dever e leis morais". Quer dizer, há a pressuposição de um objeto (idéia comum de dever e leis morais) a ser analisado e justificado pela filosofia moral. Contudo, é preciso notar que a pressuposição de Kant não interdita a tarefa filosófica de justificação da moralidade. Nesse caso, não há da parte de Kant um pedido a que os leitores da FMC simplesmente aceitem a existência de incondicionalidade da lei moral ${ }^{6}$. O esclarecimento dado por Kant no final do prefácio, a saber, a informação sobre o método analítico nas duas primeiras seções e sintético na terceira sinaliza claramente a preocupação de Kant em consignar seu compromisso com a oferta de uma justificação à moralidade ${ }^{7}$. A propósito, o próprio objetivo expresso da $F M C$ é busca e fixação do princípio supremo da moralidade. Bem entendido, não se trata apenas de buscar, mas também de fixar.

Não é, pois, verdade que Kant se exima de uma investigação com vistas a demonstrar a realidade objetiva do princípio supremo da moralidade. Sendo assim, a afirmação de Tugendhat, que faz eco às críticas de Schopenhauer, de que Kant, no prefácio da $F M C$, "insiste sem ulterior esclarecimento" (TUGENDHAT 1997, p. 108) na necessidade absoluta da lei moral não procede. A tentativa de demonstração da realidade objetiva da moralidade também pode ser verificada na $F M C$ a partir da pergunta sobre a possibilidade do imperativo da moralidade (Cf. FMC II BA 48/Ak 419). Ora, em FMC III Kant se dedica precisamente à tarefa de justificar a

\footnotetext{
${ }^{6}$ Segundo Guido de Almeida, essa afirmação inicial de Kant precisa ser entendida "não como uma tomada de posição, mas antes como uma nota promissória a ser resgatada no correr de sua investigação" (ALMEIDA 2008: 45).

${ }^{7}$ É interessante lembrar que em CRPr A 16n., Kant afirma que deve ser primeiramente debatido se 0 princípio supremo da filosofia é empírico. Deve-se notar que o método de exposição na $C R P r$ não segue a ordem estabelecida para a FMC.
} 
moralidade a fim de provar que ela não representa uma quimera, ou um fantasma de nosso cérebro.

\section{Do Caráter Imperativo da Ética ${ }^{8}$}

De acordo com Kant, na filosofia prática "não temos de determinar os princípios do que acontece mas sim leis do que deve acontecer, mesmo que nunca aconteça” (FMC II BA 62/ Ak 427). Schopenhauer se volta contra essa opinião e alega que a filosofia deve permanecer sempre teoria, pois "a sua essência é manter, perante todo objeto que a ela se oferece, o papel de simples espectador, do investigador; fazer prescrições não é o que lhe convém” (MVR IV § 53: 285) ${ }^{9}$. Sendo assim, a finalidade de uma reflexão filosófica sobre a moral deve se limitar apenas à exposição racional das ações humanas. (Cf. SFM $\S 4)^{10}$. Conseqüentemente, o caráter prescritivo da filosofia moral de Kant não pode ser aceito. Schopenhauer parece estar certo ao defender que o discurso filosófico não tem competência para dizer o que os homens devem ou não fazer. $\mathrm{O}$ que compete a ele é tão somente apreciar o que está implicado no agir. Para Schopenhauer, a ética deve ser descritiva e trilhar o caminho empírico ${ }^{11}$. Ele se pronuncia claramente a favor da ideia de que a finalidade da ética consiste em "esclarecer, explicar e reconduzir à sua razão última os modos muito diferentes de agir dos homens no aspecto moral. Por isto, resta apenas para a descoberta do fundamento da ética o caminho empírico” (SFM § 13: 113) ${ }^{12}$.

\footnotetext{
${ }^{8}$ Não distingo, nesse texto, ética de moral.

9 Itálicos meus.

${ }_{10}$ SFM, § 4, p. 21: "Digo, contrapondo-me a Kant, que em geral tanto o ético quanto o filósofo tem de contentar-se com a explicação e com o esclarecimento do dado, portanto com o que é". Veja também sobre esse ponto em Cacciola (1994: 154 e ss).

${ }^{11}$ É digno de registro o elogio de Schlick a Schopenhauer a respeito da perspectiva empírica que se deveria adotar na ética. Em "What is the aim of Ethics?", Schlick afirma: "O problema central da ética diz respeito à explicação causal do comportamento moral; em relação a esse problema todos os outros se reduzem ao nível de questões preliminares ou subordinadas. 0 problema moral foi formulado desse modo com a maior clareza por Schopenhauer, cujo profundo sentido da realidade o levou a dar o passo certo aqui (embora não na solução) e se proteger assim da formulação kantiana do problema e da filosofia pós-kantiana do valor" (SCHLICK 1959: 263).

12 "Como para o homem só o empírico ou o que porventura é empiricamente existente tem realidade pressuposta, a motivação moral tem de ser, de fato, empírica (...) Pois a moral tem a ver com a ação efetiva do ser humano e não com castelos de cartas apriorísticos" (SFM § 6: 48). Eis um ponto em que, evidentemente, nenhum acordo entre Schopenhauer e Kant é possível. Para Kant, o caminho empírico é trilhado pelo princípio da causalidade natural, o qual jamais permite a ponderação moral das ações humanas. Não por acaso, Schopenhauer nega a liberdade da vontade (individual) e se alinha à tradição
} 
Todavia, a alegada diferença de tratamento das questões morais entre a sua filosofia e a kantiana, por si só, não parece convencer. Com efeito, a pretensão que Schopenhauer atribui à filosofia moral também pode ser considerada a pretensão de Kant. Se Schopenhauer pretende com sua crítica voltar-se contra qualquer discurso moralizador, talvez ele tenha errado o alvo. Pode-se dizer que tampouco Kant pretende moralizar. A pretensão de Kant é esclarecer o que significa agir moralmente. De acordo com Guido de Almeida, na FMC Kant procura, atendendo ao que uma teoria filosófica sobre a moralidade tem de atender, responder a duas questões: "(1) O que devemos entender por 'dever moral'? (2) Por que acreditamos que temos 'deveres morais'?” (ALMEIDA 1992: 95) ${ }^{13}$. Isso significa que, também para Kant, a filosofia deve evitar fazer prescrições, até porque o conceito de dever "reside já no bom senso natural (natürliche gesunde Verstand)"14, mais precisando "ser esclarecido do que ensinado" (FMC I BA 8/Ak 397) ${ }^{15}$.

Isso que venho argumentando converge perfeitamente com a definição kantiana de filosofia segundo a qual "a Filosofia é o conhecimento racional a partir de meros conceitos” (Lógica A 22/Ak 23) ${ }^{16}$. A filosofia apenas visa à exposição de conceitos e não à sua construção. Essa segunda tarefa pertence à matemática, também uma espécie de conhecimento racional. Kant quer, com essa definição, chamar a atenção para o fato de que, na filosofia, os conceitos não são construídos pelos filósofos. São conceitos dados e, como ele alerta na $C R P$, as definições filosóficas devem ser entendidas apenas como "exposições de conceitos dados (nur als Expositionen gegebener ... Begriffe)” (CRP B 758) e, por isso, não podem ser confundidas com as definições matemáticas, que são "construções de

compatibilista de Hobbes, Spinoza, Locke e Leibniz. É digno de nota que Schopenhauer não veja, com respeito a esse ponto, isto é, à teoria da liberdade kantiana, uma diferença colossal entre seu pensamento e o do autor da FMC. Na verdade Schopenhauer tende a ler Kant como compatibilista. Portanto, onde Schopenhauer tende a ver um acordo, há, na verdade, um desacordo, e onde ele acredita ter visto um desacordo (sobre a pretensão descritiva da filosofia) eu sustento que há um acordo. ${ }^{13}$ Sobre isso, vale citar também Macintyre (1970). Macintyre fala em análise post eventum na filosofia moral de Kant (1970: 186).

14 Traduzir essa expressão não é uma tarefa simples. A opção pela literalidade, isto é, traduzir natürliche gesunde Verstand por são entendimento natural parece não ser muito adequada. Embora tenha dúvidas acerca da opção de Quintela, não consigo descortinar uma melhor. As coisas seriam mais fáceis se Kant tivesse usado a expressão do título da primeira seção, gemeinen sittlichen Vernunft.

${ }^{15} \mathrm{~A}$ bem da verdade, poderíamos dizer que não se trata de mais ou menos, ou seja, de precisar de menos ensinamento e mais esclarecimento. Numa perspectiva meramente filosófica, a razão moral comum precisa apenas de esclarecimento.

${ }^{16}$ Cf. também CRP B 741, B 865 e 868. 
conceitos originariamente formados” (CRP B 758). Por conseguinte, boa vontade, dever, mandamento, lei moral e imperativo são conceitos que a filosofia tematiza a fim de esclarecer noções já presentes no entendimento moral comum ${ }^{17}$. Sendo assim, o apelo inicial da acusação de Schopenhauer parece perder bastante o seu peso. Com efeito, a tarefa do filósofo, para Kant, estaria muito longe de qualquer proselitismo, pois sequer caberia ao filósofo a construção dos conceitos por ele tematizados.

De acordo com Schopenhauer, "seria tão tolo esperar que nossos sistemas morais e éticos criassem caracteres virtuosos, nobres e santos, quanto que nossas estéticas produzissem poetas, artistas plásticos e músicos” ( $M V R$ IV $\S 53$, p. 354$)^{18}$. Mas se Schopenhauer pretende atingir Kant com a observação de que livros de filosofia moral não fomentam virtudes em seus leitores, assim como livros de estética não produzem artistas, ele erra o alvo. Com efeito, Kant não pretende com a $F M C$ ou a $C R P r$ tornar os homens melhores moralmente. Embora Kant declare que a filosofia moral pura ajude a evitar a corrupção (Verderbnis) dos costumes (Cf. FMC prefácio BA X/Ak 390), podemos considerar essa declaração como inessencial para o propósito filosófico de sua reflexão moral, a saber, buscar e estabelecer o princípio supremo da moralidade (Cf. FMC prefácio XV/Ak 392). Assim, pode-se afirmar que também Kant diria que livros de ética não tornam os homens moralmente melhores ${ }^{19}$ Schopenhauer talvez insistisse sobre o equívoco da

\footnotetext{
${ }^{17}$ Nessa mesma linha, ver Guido de Almeida (2008: 49).

18 Young (2005) acredita ter detectado uma contradição em Schopenhauer. O comentarista alega que a filosofia de Schopenhauer contém elementos prescritivos. Sendo assim, Schopenhauer não seria consistente ao negar que a filosofia possa ser prática. Young vê no MVR IV diversas prescrições filosóficas. Ele argumenta que a própria alegação de Schopenhauer segundo a qual a filosofia deve manter a atitude de pura contemplação, isto é, de permanecer sempre como teoria, já poderia indicar uma autocontradição, pois se estaria filosoficamente prescrevendo como devemos fazer filosofia (Young 2005: 166). Young cita também a descrição da vida dos santos em MVR IV (2005: 167). Ele entende que essa descrição representa a apresentação de um modo de vida que mereceria ser imitado. Logo, estaria contida na descrição da vida dos santos uma exortação para que seguíssemos seus exemplos. Porém, a meu ver, Young está errado. Penso que poderíamos, em defesa de Schopenhauer, apresentar a seguinte resposta. Em que pese a possibilidade de efeitos colaterais práticos da filosofia, o ponto de Schopenhauer consiste em perceber a natureza descritiva da filosofia. Ou seja, Schopenhauer pode ser defendido como alguém que sustenta que não é objetivo da filosofia prescrever, não que ela não possa influenciar nossas ações. E parece inofensivo o reconhecimento de que a possibilidade da filosofia influenciar nossas ações não a torna prescritiva (no sentido de exortação).

${ }^{19}$ É verdade que Kant não concordaria que os homens não podem se tornar melhores do que são. Aqui sim há uma diferença profunda entre Kant e Schopenhauer. Schopenhauer é um fatalista (Cf. MVR IV $\S$ 55, p. 395). Schopenhauer defende a tese de que não está em nosso poder sermos bons ou maus, tese que ele pensa já estar em Sócrates e em Aristóteles (Cf. SFM § 19: 182). Em contrapartida, Kant defende, como incompatibilista, a liberdade da vontade (não da Vontade, como coisa-em-si,o que faz
} 
afirmação de Kant na $F M C$ de que na filosofia prática "não temos de determinar os princípios do que acontece mas sim leis do que deve acontecer, mesmo que nunca aconteça” (FMC II BA 62/Ak 427). É coerente sustentar que a filosofia moral de Kant visa à explicação do dado, que são nossas crenças na idéia de dever moral, e ainda assim procure determinar leis do que deve acontecer, mesmo que nunca aconteça? O que significa "determinar leis do que deve acontecer, mesmo que nunca aconteça"? Determinar, aqui, não significa impor leis, a exemplo da imposição de leis que um soberano político pode fazer em relação a seus súditos. Determinar leis significa estabelecer por análise quais são as leis do dever moral. Significa portanto analisar, explicar, não fazer exortações e fugir dos "fatos" (entendendo aqui por fato, não um fenômeno a ser explicado, mas um dado da razão a ser

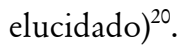

Intimamente ligada à crítica à suposta índole prescritiva da filosofia moral kantiana está o argumento de Schopenhauer contra a natureza categórica do imperativo da moralidade em Kant. Schopenhauer pretende mostrar que nenhum imperativo pode ser categórico, pois para ele só existem imperativos hipotéticos. O imperativo da moralidade em Kant quer ser uma coisa que nenhum imperativo poderia ser (Cf. SFM § 7: 67).

É preciso ainda dizer que a crítica de Schopenhauer à natureza prescritiva da ética em Kant parece não entender que o caráter prescritivo da ética significa tão-somente que o sujeito, ao reconhecer o valor moral de uma determinada ação (ou princípio da ação), reconhecerá, ao mesmo tempo, que tal ação ou princípio traz consigo uma exigência para seu acatamento, quer dizer, ele reconhecerá que há uma razão para agir com base nesse princípio ${ }^{21}$. Isso, como se pode ver, não implica qualquer proselitismo filosófico, mas simplesmente o reconhecimento de como "funciona" moralmente o entendimento comum.

Schopenhauer), ou se preferirmos o uso ulteriormente sofisticado, a liberdade do arbítrio (Cf. Religião B 11/ Ak 23 e MC Ak 226).

${ }^{20}$ Estou de pleno acordo com a afirmação de Höffe segundo a qual Kant não faz proselitismo moral na FMC ou CRPr. "Kant não levanta o dedo indicador, mas fala sobriamente uma linguagem cognitiva e não uma linguagem normativa. Em oposição a um moralizar precipitado, ele começa com um fenômeno moralmente neutro, a faculdade não de agir segundo as leis da natureza previamente dadas, mas de representar a si mesmo leis, por exemplo, relações meio-fim, de reconhecer as leis representadas como princípios e agir segundo eles" (HÖFFE 2005: 188).

${ }^{21}$ Esse ponto é muito bem assinalado por Walker (1999: 18). 


\section{A moral teológica em Kant}

Mas Schopenhauer poderia dizer que não é esse exatamente o ponto, isto é, do mero reconhecimento do "modo de ser" do entendimento moral comum. Ele poderia insistir na idéia de que a moral não deve ter uma forma imperativa, pois esta forma só poderia repousar em fundamentos teológicos (SFM § 4). Acredito que isso representa sim uma discordância decisiva com a abordagem empreendida por Kant. Com efeito, para o autor da FMC a forma imperativa da moral, tal como ele pensa ter esclarecido e justificado, não tem qualquer fundamento teológico, do contrário a autonomia da vontade jamais poderia ser o "princípio supremo (oberstes Prinzip) da moralidade” (FMC II BA 88/Ak 440).

A fim de dar conta de seu declarado objetivo, como já dito, o da "busca e fixação do princípio supremo da moralidade" (FMC prefácio BA XV/Ak 392), Kant entende que não basta esclarecer como os homens agem, mas como devem agir. Se a investigação sobre a ética tivesse de se restringir ao exame empírico das ações humanas, tal estudo poderia ser ainda um estudo pertencente à ética, mas não à filosofia moral, não à "moral propriamente dita” (FMC prefácio BA V/Ak 388). Um exame das ações humanas baseado na experiência deve receber o nome de "antropologia prática”, constituindo-se, assim, o que Kant entende ser justamente a parte empírica da ética ${ }^{22}$. Deve-se, contudo, reconhecer que Schopenhauer está atento a isso. Sua discordância parece ser uma discordância radical. No § 13 de $S F M$, ele retoma esse ponto.

Talvez se queira objetar-me que a ética nada tem a ver com o fato de como os homens efetivamente agem, mas que ela é a ciência de como devem agir. Mas é justo esse princípio que eu nego (...), o conceito de dever, a forma imperativa da ética só

\footnotetext{
${ }^{22}$ Como eu disse atrás que não distingo nesse texto entre ética e moral, talvez seja oportuno advertir que Kant, no prefácio da FMC, refere-se à ética e à moral como coisas não completamente indistintas. Kant pensa a ética como uma das três divisões da filosofia (ao lado da lógica e da física). A ética se ocuparia das leis da liberdade e seria dividida em "antropologia prática" (parte empírica) e a "moral propriamente dita" (parte racional) (FMC prefácio BA VI Ak 388). Sendo assim, poder-se-ia pensar numa distinção entre ética e moral análoga à diferença entre um gênero (ética) e uma de suas espécies (moral). Na DV, como se sabe, o termo ética se restringirá à "doutrina da virtude" (DV Ak 375, 379).
} 
são válidos na moral teológica e que perdem todo o sentido e significação fora dela. $(S F M \S 13: 113)^{23}$.

Como se percebe, a discussão sobre a divergente concepção de filosofia moral entre Schopenhauer e Kant nos conduz à discussão sobre a suposta presença, disfarçada, da teologia no centro da ética de Kant.

Ora, sobre esse ponto, o que parece ter Schopenhauer mostrado foi que os conceitos de dever e a forma imperativa da ética também são conceitos empregados pela moral teológica. Contudo, Schopenhauer não conseguiu estabelecer que eles somente adquirem sentido dentro da moral teológica. Com base em que ele alega que os conceitos de dever e afins são necessariamente teológicos? Não é lícito inferir do fato de eles serem encontrados na moral teológica que eles são necessariamente teológicos. Não há nenhuma dificuldade em perceber a inconsistência do seguinte raciocínio:

A moral teológica contém os conceitos de dever, lei e mandamento.

Ora, a moral kantiana contém os conceitos de dever, lei e mandamento.

Logo, a moral kantiana é uma moral teológica.

Para que a conclusão fosse suportada pelas premissas seria preciso justificar a alegação implícita de que os conceitos de dever, lei e mandamento são necessariamente teológicos, o que Schopenhauer não consegue fazer. Admitamos que os conceitos de dever, lei e mandamento sejam constituintes da moral teológica e da moral kantiana. Disso não podemos, sem mais,

\footnotetext{
${ }^{23}$ Como se sabe Kant se pronuncia expressamente contra a moral teológica, embora não contra uma teologia moral. A moral teológica <theologische Moral> "contém leis morais que pressupõem a existência de um soberano governante do mundo, enquanto a teologia moral $<$ Moraltheologie $>$ funda sobre leis morais a crença na existência de um ser supremo" (CRP B 660, nota). Na CFJ pode-se ler: "é perfeitamente possível uma teologia ética <Ethikotheologie>, pois a moral pode na verdade subsistir, com sua regra, sem teologia (...) Mas uma ética teológica <theologische Ethik> (da razão pura) é impossível, porque leis que a razão não dá ela própria originalmente e cujo cumprimento ela também não realize, enquanto faculdade prática pura, não podem ser morais" (CFJ B 482). "A moral, em prol de si própria (tanto objetivamente, no tocante ao querer, como subjetivamente, no que diz respeito ao poder), de nenhum modo precisa da religião, mas basta-se a si própria em virtude da razão pura prática" (Religião BA III-IV). Cf. também FMC II BA 32-33/Ak 410, CRPr A 232-233. Há, porém, como destacarei ao final, inconsistências de Kant no Cânon da CRP sobre a relação entre Deus, imortalidade e moralidade.
} 
pensar que eles sejam qualificadores exaustivos de nenhuma delas. De fato, não são, pois na moral teológica é preciso recorrer ao conceito de Deus e na moral kantiana ao conceito de autonomia da vontade (sem Deus evidentemente).

Poder-se-ia conceder a Schopenhauer procedência em sua crítica se ele restringisse o seu alcance apenas à Primeira $C_{r i t i c a}{ }^{24}$. Realmente, no Cânon da $C R P$, há elementos abonadores à leitura de Schopenhauer. Na CRP, Kant sustenta a necessidade da razão admitir a existência de Deus e da imortalidade da alma a fim de não se considerar as leis morais como "vãs quimeras, pois a conseqüência necessária que a razão vincula a essas leis, sem estes pressupostos, está condenada a desaparecer” (CRP B 839). Ora, essa passagem, à luz dos argumentos da $F M C$, parece profundamente questionável. Na Crítica da Faculdade do Juízo, Kant advoga, em consonância com a tese da autonomia da vontade, que todo e qualquer ser racional, seja crente em Deus, ateu ou agnóstico, tem de reconhecer-se estreitamente ligado às prescrições da moralidade (Cf. CFJ § 87/B 425). Por conseguinte, é defensável a ideia de que as leis morais não podem ser tidas como quimeras para quem não acolhe Deus e a imortalidade da alma como pressuposições. Kant também declara, no Cânon da Primeira Crítica, que "sem um Deus e sem um mundo atualmente invisível para nós, mas esperado, são as magníficas idéias da moralidade certamente objetos de aplauso e admiração, mas não molas propulsoras (Triebfedern) de intenção e de ação" (CRP B 841). Mais uma afirmação, a meu ver, conflitante com as teses da FMC. Estas duas passagens (a de B 839 e B 841) seriam sim um abono inicialmente aceitável para a crítica de Schopenhauer sobre a presença da teologia na base da moral kantiana. Sendo assim, parece-me justificável afirmar que o Cânon não representa a filosofia moral crítica de Kant, posição que me leva a concordar, em linhas gerais, com Allison (1990: 46) e Almeida (1997: 176-177). Talvez se possa defender que, no Cânon, o princípio da autonomia da vontade esteja hesitantemente implícito em algumas passagens. De todo modo, o princípio da autonomia da vontade não opera decisivamente na compreensão que Kant tem sobre a liberdade e a motivação moral.

${ }^{24}$ Esse ponto é corretamente assinalado por Young (Cf. 1984: 209). 


\section{Referências Bibliográficas}

ALLISON, H. E. Kant's theory of freedom. New York: Cambridge University Press, 1990.

ALMEIDA, G. A. de. "Moralidade e Racionalidade na Teoria Moral Kantiana”. In ROHDEN, V. (org). Racionalidade e Ação. Porto Alegre: UFRGS e Instituto Goethe, 1992, p. 94-103.

. "Moralidade e liberdade segundo Kant”. In Analytica, vol. 2, n.1, 1997, p.

$175-202$.

- "O conceito kantiano de filosofia e a Fundamentação da Metafísica dos

Costumes”. In PERES, D. T. et al. (Org.). Tensões e Passagens - Filosofia Crítica e Modernidade: uma homenagem a Ricardo Terra. 1. ed. São Paulo: Esfera Pública, 2008, p. 43-58.

BECK, L. W. A Commentary on Kant's Critique of pratical reason. Chicago: The University of Chicago Press, 1966.

BIRNBACHER, D. "Arthur Schopenhauer: vontade e negação do mundo". In FLEISCHER, M. e HENNIGFELD, J. (org). Filósofos do século XIX. Uma introdução. Tradução de Danwart Bernsmüller. São Leopoldo: Ed Unissinos, 2004, p. 156-180.

CACCIOLA, M. L. M. e Oliveira: Schopenhauer e a questão do dogmatismo. São Paulo: Edusp, 1994.

EBBINGHAUS, J. "Interpretation and Misinterpretation of the Categorical Imperative”. In The Philosophical Quarterly, Vol. 4, No. 15 (Apr., 1954), pp. 97-108.

HÖFFE, O. Introduction à la philosophie pratique de Kant. La morale, le droit e la religion. Tradução de Francois Rüegg e Stéphane Gillioz. Paris: Vrin, 1993.

Immanuel Kant. Tradução de Christian Viktor Hamm e Valério Rohden.

São Paulo: Martins Fontes, 2005.

KANT, I. Werke in Zwölf Bande. Ed. W. Weischedel. Frankfurt: Surkamp, 1991.

. "Sobre a expressão corrente: isto pode ser correcto na teoria, mas nada vale na prática”. In A paz perpétua e outros opúsculos. Tradução de Artur Morão. Lisboa, Ed. 70, 1988, p. 57-102.

À paz perpétua. Tradução de Marco A. Zingano. Porto Alegre: L\&PM, 1989.

. A Religião nos limites da simples razão. Tradução de Artur Morão. Lisboa: Ed. 70, 1992.

Anthropologie du point de vue pragmatique. Tradução de Michel Foucault. Paris: J. Vrin, 1964. 
. Crítica da Faculdade do Juízo. Tradução de Valério Rohden e Antonio Marques. Rio de Janeiro: Forense, 1993.

. Crítica da Razão Prática. Tradução com introdução e notas de Valério Rohden. São Paulo: Martins Fontes, 2002.

- Crítica da Razão Pura. Tradução de Manuela Pinto dos Santos e Alexandre Fradique Morujão. Lisboa: Calouste Gulbenkian, 1994.

- Fundamentação da Metafísica dos Costumes. Tradução de Paulo Quintela. Porto: Porto Editora, 1995.

. La Metafísica de las Costumbres. Tradução de Adela Cortina Orts e Jesus Conill Sancho. Madrid: Tecnos, 1994.

Lecciones de Ética. Tradução de Roberto Rodriguez Aramayo e Concha Roldan Panadero. Barcelona: Crítica, 1988.

Lógica. Tradução de Guido de Almeida. Rio de Janeiro: Tempo Brasileiro, 1992.

MACINTYRE, A. História de la ética. Buenos Aires: Paidos, 1970.

PATON, H. J. The Categorical Imperative: A Study in Kant's Moral Philosophy. London: Hutchinson, 1970.

SCHLICK, M. "What is the aim of Ethics?". In AYER, A. J. (ed). Logial Positivism. New York, Londom: Free Press, 1959.

SCHOPENHAUER, A. Preisschrift Über die Freiheit des Willens. Sämtliche Werke, Band III: Bearbeitet und Heraugegebt von Wolfgang Frhr. Von Löhnheysen. Frankfurt am Main: Suhrkamp, 1998.

. Crítica da Filosofia Kantiana. Tradução de Maria Lúcia Cacciola. São Paulo: Nova Cultural, 1988 (Os Pensadores).

. Essai sur le Libre Arbitre. Tradução de Salomon Reinach. Paris: Félix Alcan, 1925.

. O Mundo Como Vontade e Representação. Primeiro tomo. Tradução, apresentação, notas e índices por Jair Barboza. São Paulo: Unesp, 2005.

. Sobre o Fundamento da Moral. Tradução de Maria Lúcia Cacciola. São Paulo: Martins Fontes, 1995.

. Parerga e Paraliponema, capítulos V, VIII, XII, XIV. Tradução de Wolfang Leo Maar. São Paulo, Nova Cultural, 1988 (Os Pensadores).

Über die Grundlage der Moral. Kleinere Schriften. Sämtliche Werke, Band III: Bearbeitet und Heraugegebt von Wolfgang Frhr. Von Löhnheysen. Frankfurt am Main: Suhrkamp, 1998, p. 629-815.

TUGENDHAT, E. Lições sobre Ética. Tradução do grupo de doutorandos do Curso de Pós-Graduação da UFRGS, revisão e organização da tradução de Ernildo Stein e Ronai Rocha. Petrópolis: Vozes, 1997. 
WALKER., R. Kant: Kant e a lei moral. Tradução de Oswaldo Giacóia Junior. São Paulo: Ed. Unesp, 1999.

WELSEN, P. "Schopenhauer's Interpretation of the Categorical Imperative". In Revista Portuguesa de Filosofia. V. 61, n.3-4, 2005, p. 758-772.

YOUNG, J. “Schopenhauer's Critique of Kantian Ethics". In Kant-Studien 75 (2), 1984, p. 191-212.

. Schopenhauer. Londres e Nova York: Routledge, 2005.

Email: aguinaldo.pavao@uol.com.br

Recebido: outubro/2009

Aprovado: novembro/2009 